\title{
Una propuesta metodológica para identificar gentrificación a partir de los censos de población
}

\section{A census based methodological approach to gentrification recognition}

\author{
Ibán Díaz Parra* \\ Ricardo Apaolaza**
}

\begin{abstract}
Resumen
En el actual cuerpo de estudios sobre gentrificación en América Latina han predominado los estudios de caso centrados en áreas focalizadas y con un tratamiento predominantemente cualitativo. Ante este escenario, uno de los retos presentes es desarrollar metodologías que permitan trabajar en escalas mayores, que sean replicables y que permitan establecer comparaciones, sin por ello renunciar a los estudios de caso en profundidad. La bibliografia internacional muestra las potencialidades de la estadistica censal para este menester, la necesidad de combinar variables de estatus social y condiciones de la vivienda, así como la pertinencia de entender el proceso como un cambio relativo de zonas específicas con respecto del conjunto de la ciudad y con una temporalidad amplia. A partir de estas ideas, se recurre a los censos de población y vivienda en la Ciudad Autónoma de Buenos Aires y se propone una metodología que cumple con la doble función de identificar áreas con indicios de procesos de gentrificación en curso, asi como de reconocer posibles características sociohabitacionales que las harian potencialmente más "gentrificables". El texto concluye señalando la factibilidad de la metodología propuesta, asi como la necesidad de examinar las potencialidades y limitaciones de cada censo nacional cuando se realizan comparaciones entre distintos paises.
\end{abstract}

* Universidad de Sevilla, Departamento de Geografía Humana. Dirección: Doña María de Padilla, s/n, 41004, Sevilla, España. Correo: ibandipar@gmail.com ORCID http://orcid. org/0000-0002-4159-3338

** Universidad de Buenos Aires, Instituto de Geografía Romualdo Ardissone. Dirección: Puan $480,4^{\circ}$ piso, Facultad de Filosofía y Letras, C1406, Ciudad Autónoma de Buenos Aires, Argentina. Correo: ricardoapaolaza@yahoo.com.ar ORCID: https://orcid.org/0000-0002$3684-8623$ 
Palabras clave: gentrificación; gentrificabilidad; segregación socioespacial; censos de población.

\begin{abstract}
Current research on gentrification in Latin America shows a predominance of case studies, most of which focuses on specific areas using qualitative approaches. In this context, one of the main challenges is to develop methodologies to produce replicable and comparable information, enabling larger scales' analysis. The international literature recognizes the potential of census statistics for meeting this goal, highlighting the need to combine both variables of social status and housing conditions. It also points out the importance of addressing the process as a local/neighbourhood change that needs to be analyzed in a whole-city scale and with a broad temporality. Based on these ideas, this work explores the population and housing censuses for Buenos Aires autonomous city and proposes a specific methodology to detect potential gentrifying areas, as well as correlated variables that come out to explain what may make these areas more "gentrificable". The text concludes by evaluating the potentiality of this methodology, as well as warning about the heterogeneities and limitations of each national census when making comparisons between different countries.
\end{abstract}

Keywords: gentrification; gentrificability; socio-spatial segregation; population census

\title{
1. Introducción
}

El reciente interés por la gentrificación en América Latina se genera luego de al menos dos décadas de reinversiones de capitales en los centros urbanos de las ciudades de la región, ya sea para explotación turística, desarrollo de enclaves comerciales o promoción de residencia para grupos solventes, y se explica en parte por la progresiva visibilización de las consecuencias negativas asociadas a esta "revalorización".

En este contexto, los esfuerzos comparativos Sur-Sur se han multiplicado, incorporando variados enfoques y escalas de análisis (Janoschka, Sequera y Salinas, 2013; Salinas, 2013; Janoschka y Sequera, 2016; López-Morales, Bang Shin y Lees, 2016; Alexandri, González y Hodkinson, 2016). En este reciente auge de trabajos latinoamericanos que utilizan el concepto de gentrificación existe una clara mayoría de los que se basan en estudios de caso, generalmente a nivel de "barrio", usando principalmente datos cualitativos. Algunas compilaciones recientes de trabajos sobre el tema son un buen ejemplo de ello (e. g., Delgadillo, Díaz Parra y Salinas, 
2015). Así, se ha acumulado una gran cantidad de evidencia que permite corroborar la existencia de fenómenos similares en toda la región y que denuncia los efectos perniciosos relativos al desplazamiento de población y a los usos populares tradicionales, así como el reforzamiento de ciertas pautas de segregación y de injusticia socioespacial en la reestructuración neoliberal de la ciudad.

Este texto se sitúa en una posición afín a las perspectivas críticas sobre tal tipo de procesos, especialmente con las explicaciones desde la teoría de la renta y la producción capitalista del espacio (por ejemplo, los trabajos de Neil Smith aquí citados). No obstante, que haya que ir más allá de lo evidente no debería implicar prescindir de la evidencia, y este estudio pretende cubrir lo que identificamos como una carencia en este sentido, no tanto en cuanto compilación de descripciones de injusticias flagrantes, fruto de la forma que toman los procesos de renovación urbana, como en cuanto a indicadores que permitan trabajar a otras escalas, comparar casuísticas y justificar el desarrollo de políticas preventivas. De igual forma, estamos prevenidos contra las generalizaciones espurias y las relaciones de dependencia con la academia de los países centrales (que advertiría Pradilla Cobos, en Delgadillo, 2013), lo que para nosotros implica aprovechar las buenas aportaciones teóricas y metodológicas desarrolladas en otras geografías, poniéndolas siempre en diálogo crítico con la realidad y las investigaciones latinoamericanas.

En este punto, resulta fundamental destacar las diferencias substanciales (en cuanto a niveles de consolidación urbana, a contenido social, etc.) que existen entre los "centros" y las "periferias" de las ciudades latinoamericanas y los de las ciudades anglosajonas. Esto ayuda a entender la enorme magnitud de las pérdidas asociadas al desplazamiento del centro sufrido por los sectores populares y su posterior confinamiento en las periferias precarias. Se trata de consecuencias que en modo alguno se resumen a pérdidas residenciales, sino que incluyen una serie de fuertes impactos negativos asociados, como la desarticulación laboral, la destrucción de lazos sociales o hasta el estrés y la vulnerabilidad psicofísica e identitaria (Blanco y Apaolaza, 2016; Apaolaza, 2018).

Por otro lado, todavía se evidencia una falta de análisis a cierta escala y siguen sin encontrarse metodologías que permitan una aproximación comparativa y sistemática al problema. No es ajena a estas carencias la ausencia de políticas dirigidas a combatir los efectos negativos de la gentrificación (Harvey, en Martí y Salazar, 2016). Efectivamente, plantear políticas requiere de manejar información sistemática a lo largo del tiempo, con capacidad para evaluar la existencia de este tipo de procesos y su grado 
de incidencia en diferentes ciudades. Además, intervenir sobre los efectos negativos de la gentrificación implica prestar atención, más que a procesos que ya se han cristalizado, a la posibilidad de prever la ocurrencia de los mismos. Los variados y tempranos antecedentes existentes sobre políticas antidesplazamiento (Marcuse, 1985; Levy, Comey y Padilla, 2006; Bates, 2013) dejan en claro la importancia de anticipar (y alertar sobre) los procesos de gentrificación, antes que correr detrás de ellos intentando hacer un recuento de unos daños y efectos negativos que, muchas veces, son irreversibles (Blanco y Apaolaza, 2016). Trasladado a la contienda política, esto conlleva pugnar para que el foco deje de ser la discusión sobre la existencia o no (y medición) del desplazamiento, y pase a ser la discusión sobre la existencia o no de instrumentos y evaluaciones que aseguren el "no desencadenamiento" de tal proceso.

Para ello, y sin negar la utilidad de otros enfoques ni la necesaria articulación con metodologías de carácter cualitativo, se torna evidente la necesidad de una aproximación sistemática que utilice variables significativas para un territorio amplio y en una dimensión temporal, con la suficiente profundidad como para captar un proceso que es dinámico por definición. Tal escala y sistematicidad de abordaje no pueden ser resueltas a partir de aproximaciones de caso, sino que requieren utilizar la información estadística preexistente, por lo que los censos de población terminan por ser la mejor opción. A pesar de los importantes obstáculos que su uso encuentra, el mejoramiento de los censos en la región es notable, y hay una tendencia a facilitar la comparación entre distintos sistemas estadísticos gracias al trabajo de instituciones como el Centro Latinoamericano y Caribeño de Demografía (Celade), dentro de la Comisión Económica para América Latina y el Caribe (CEPAL, 2017).

El presente artículo pretende contribuir en esta dirección, a partir del análisis de la Ciudad Autónoma de Buenos Aires (CABA), capital de la República Argentina y centro de una extensa área metropolitana de más de 13 millones de habitantes. Para ello, se plantea por objetivo la selección de indicadores de gentrificación y de gentrificabilidad (véase el siguiente apartado), tomados de los Censos Nacionales de Población, Hogares y Viviendas de Argentina (INDEC, 2001 y 2010), experimentando así con una metodología reproducible y generalizable a un importante número de casos en América Latina. 


\section{Problematización teórico-conceptual}

\subsection{Gentrificación y gentrificabilidad como conceptos analíticos}

Está claro que los instrumentos estadísticos que se seleccionen como indicador de gentrificación dependerán directamente de la forma en que se entienda y defina el fenómeno. En este sentido, la discusión dentro de la literatura en español sigue sin hallar consenso, fundamentalmente debido a la ausencia de un debate claro: muchos trabajos e investigaciones utilizan el concepto de manera paralela y sin entrar en diálogo entre sí. A continuación, se revisan algunas de las perspectivas más valiosas y relevantes.

En primer lugar, existe una tendencia a vincular unívocamente gentrificación con desplazamiento de población o incluso con cualquier construcción neoliberal de ciudad, en la medida en que la urbanización neoliberal siempre implica algún tipo de desplazamiento o exclusión. No obstante, esto conlleva una excesiva flexibilización del término, que acaba por referir a procesos muy diversos, desde cambios de usos industriales por residenciales a la creación de urbanizaciones cerradas en la periferia urbana (Slater, 2009; Casgrain y Janoschka, 2013; Lees, 2013; y Janoschka y Sequera, 2016).

Casgrain y Janoschka (2013), siguiendo a Lees, Slater y Wyly (2008), intentan arrojar luz sobre el asunto, incluyendo cuatro elementos que deberían coincidir para hablar de gentrificación: a) reinversión y alza del valor del suelo, $b$ ) llegada de agentes con mayor capacidad de pago, $c$ ) cambios en las actividades y el paisaje urbano, y $d$ ) desplazamiento de los grupos sociales con menores ingresos. Si bien se trata de una propuesta de interés, que enfatiza el contenido económico, social y funcional del proceso, sigue sin aportar claridad analítica, ya que enumerar una serie de condiciones no termina de suplir una definición relacional del proceso. Más bien habría que plantear cómo estos elementos se interrelacionan para dar lugar a un fenómeno particular que merece ser nombrado.

Otra posición recurrente toma por gentrificación -explícita o implícitamente- cualquier tipo de "colonización" de sectores urbanos por parte de las clases medias, que eran ajenas a ellos previamente (Hammet, 2003; Sabatini, Robles y Vásquez, 2009; 2017). Así, la gentrificación podría incluir desarrollos sobre áreas vacantes (baldías) rodeadas de barrios populares, que no sólo no generarían perjuicios para los viejos residentes circundantes, sino que incluso podrían concurrir a una mejora del tejido social a través de una reducción de la escala de la segregación (Sabatini, Robles y Vásquez, 2009), algo que ha sido fuertemente cuestionado en el caso chileno (véa- 
se, por ejemplo, Ruiz-Tagle, 2016a, 2016b; Ruiz-Tagle y López Morales, 2016).

Finalmente, López-Morales (2011) y Apaolaza, Blanco, Lerena, LópezMorales, Lukas y Rivera (2016), siguiendo los trabajos de Smith (1996) y Clark (2005), han avanzado en la identificación de los roles de los agentes fundamentales en la producción de los procesos de renovación urbana y apropiación de diferenciales de renta. Estas perspectivas son necesarias para evitar caer en el empirismo ingenuo que podría achacárseles a algunos de los autores anteriores. Sin embargo, su enfoque puede conducir a asociar gentrificación exclusivamente con la existencia de un diferencial de renta (rent gap) o con procesos de densificación susceptibles de generarlo, que nos alejan del fenómeno particular que buscamos delimitar con la noción de gentrificación. Nuestra posición es que es necesario reconocer el fenómeno en sí, sin renunciar por ello a indagar sobre los mecanismos estructurales que lo desencadenan, para lo cual creemos que los avances en la aplicación de la teoría de la renta de algunos de estos autores son fundamentales (aunque no sea un objetivo específico de este trabajo).

Ante los problemas de indefinición, resulta indispensable la aportación ya clásica de Clark (2005), bastante difundida en América Latina por los trabajos de López-Morales y Díaz Parra: entender la gentrificación no como el desplazamiento de población vulnerable ni como el asentamiento de nuevas clases medias, sino como la relación entre ambos, mediada por la inversión en el entorno construido. Así, el fenómeno tendría su expresión más evidente en el cambio de estatus social dentro de sectores urbanos sometidos a algún tipo de renovación urbana. Bajo esta perspectiva, ya no se busca cumplir una check list de atributos para hablar de gentrificación, sino con un proceso en el que el desplazamiento de usos y/o población aparece como la consecuencia lógica de la reinversión exitosa de un sector devaluado, dirigida a un grupo con mayor poder adquisitivo. Acordamos con Clark o con López-Morales, que la clave del desencadenamiento de estos procesos es la inversión de capital en el entorno construido y su relación con la oscilación en las rentas del suelo. Sin embargo, la inversión de capital y el incremento de las rentas (nuevamente) pueden tener efectos espaciales muy diferentes, y al atender el fenómeno de la gentrificación entendemos que implica observar el fenómeno de sustitución de usuarios por otros de mayor estatus.

Una cuestión fundamental a discutir se refiere a las condiciones que facilitan el desarrollo de este tipo de proceso: qué aspectos sociales, habitacionales, económicos, etc., de las diferentes zonas o vecindarios podrían facilitar el desarrollo de este tipo de estrategias de renovación expulsiva. Elegimos hablar aquí de gentrificabilidad (Díaz Parra, 2011; Apaolaza y 
Bosoer, 2014) en tanto la mayor predisposición o vulnerabilidad de los diferentes sectores urbanos a sufrir este tipo de procesos.

Por ejemplo, un elevado volumen de alquileres suele implicar una mayor movilidad, independientemente de que esto desemboque en un incremento de la proporción de propietarios o no (Herzer, 2008). Además, en muchos de los casos latinoamericanos se suma el contraintuitivo hecho de que sectores a simple vista muy vulnerables, como los ocupantes ilegales, presenten mayor capacidad de resistencia que los inquilinos, mucho más indefensos frente a los mecanismos de desplazamiento vía mercado (Blanco, Apaolaza y Lerena, 2015; González, Blanco, Bosoer y Apaolaza, 2015). Otros trabajos han señalado la mayor permeabilidad para la sustitución de población por la menor capacidad de los habitantes a desarrollar estrategias de oposición, como en el caso de la existencia de un sector relativamente despoblado, envejecido, habitado por inmigrantes vulnerables o bien por población marginal (Díaz Parra, 2011). Adicionalmente, debería sumarse la existencia de "vacantes" por viviendas vacías, baldíos o instalaciones abandonadas. Asimismo, los ya mencionados trabajos de Smith $(1982,1996)$ alertan sobre posibles devaluaciones relativas de las rentas del suelo, capaces de habilitar ganancias especulativas extraordinarias ante una eventual revalorización. Finalmente, Ley (1996) ha mostrado cómo la correlación más consistente de la gentrificación con otra variable es la proximidad a un área de élite social.

Muchos de estos aspectos son frecuentemente recogidos por los censos de población, por lo que resultaría de antemano factible construir indicadores a partir de los mismos.

\subsection{Antecedentes sobre la medición de la gentrificación}

Existe una serie de valiosos antecedentes de trabajos que abordan la gentrificación a partir de los censos. En primer lugar, debe mencionarse el trabajo de Ley (1986), que concibe dos posibilidades para identificar la gentrificación: centrarse en indicadores del mercado de la vivienda, o centrarse en indicadores de cambio social. El canadiense opta por la segunda, construyendo un indicador sobre la base del peso de los oficios profesionales y técnicos, y la proporción de universitarios, cuyo diferencial entre dos censos marcaría posibles procesos de gentrificación. Así, Ley parece tomar el cambio en el estatus social de los hogares de manera independiente del stock de viviendas, lo que le permite tomar distancia de las tesis de Smith, para luego observar la correlación de este indicador de gentrificación con 
otras variables independientes y realizar un análisis de componentes principales.

Smith (1987) critica esta aproximación, planteando que el incremento en el estatus educacional y de empleo podría darse por razones desconectadas de la gentrificación, remarcando nuevamente la importancia del cambio físico en la variable habitacional: esta combinación de cambios físicos y sociales sería el rasgo distintivo de la gentrificación. Ley (1988) terminaría el debate hablando de movilidad social ascendente en lugar de gentrificación, desarrollando una cartografía censal en la que, como resulta esperable, el incremento del estatus social es mayor donde este dato era más alto de partida.

Otros trabajos han recurrido a la construcción de indicadores complejos a partir de múltiples variables sociodemográficas, acercándose a los estudios anglosajones más centrados en la perspectiva del consumo. Un ejemplo reciente es el trabajo de Bournazou (2015) sobre la Ciudad de México, que no parece dar los frutos esperados ya que se basa en aspectos demográficos (número de hijos, envejecimiento) que pueden ser acertados en ciertos contextos (e. g., las ciudades norteamericanas en los ochenta), pero no son universalizables. Efectivamente, las variables demográficas pueden ser válidas para caracterizar la gentrificación en un determinado barrio, o incluso para identificar las características que lo hicieron gentrificable, pero no deben confundirse con el fenómeno en sí.

Otro trabajo relevante es el de Hammel y Wyly (1996). Los autores comienzan por denunciar que los estudios puramente estadísticos, desconectados de los resultados de campo, tienden a fallar a la hora de distinguir la gentrificación de otros tipos de transformaciones de sectores urbanos consolidados. En consonancia, parten de identificar la gentrificación como la combinación del cambio socioeconómico y la transformación habitacional, algo que entienden como cuasi universal bajo criterios de mercado. En consecuencia, los indicadores de gentrificación para el modelo que proponen son dos: a) secciones censales con más de un tercio de la edificación reinvertida en el periodo de estudio, y $b$ ) ingresos por hogar por debajo de la media al principio del periodo. Estos resultados son complementados por un trabajo de campo. Sobre la base de los dos indicadores identifican los sectores que se habrían gentrificado total o parcialmente. Posteriormente, utilizan el análisis de componentes para elegir las variables censales que caracterizan las áreas en las que se estarían dando estos procesos (véase también Wyly y Hammel, 1998).

Pueden asimismo mencionarse algunos trabajos de similar abordaje, que puntualmente se interesan por los efectos asociados a las inversiones 
en infraestructura y servicios de transporte, en especial en los sistemas del metro. Trabajos como los de Kahn (2007), Pollack, Bluestone y Billingham (2010) o Grube-Cavers y Patterson (2015), desarrollados en Estados Unidos y Canadá, han intentado medir y analizar el impacto del metro en la colonización de nuevos mercados inmobiliarios, a través de la atracción tanto de inversiones, como de grupos sociales de mayores ingresos.

Por último, vale mencionar el trabajo de Hammet (2003), que se basa en la revisión de estadísticas censales, en el que el proceso se resume en el cambio de estatus y ocupación laboral de los residentes de un barrio, por lo que el indicador adecuado sería el cambio en el porcentaje de profesionales y gerentes. La gentrificación es identificada entonces con el incremento de este indicador en áreas que eran previamente de clase trabajadora, tras lo cual se llega a la conclusión de que la gentrificación se produce simplemente porque hay más clase media y ésta tiende a ocupar más espacio. El trabajo se centra así en defender la idea de que la gentrificación sería una expresión espacial de la movilidad social ascendente estructural asociada al paso a una sociedad posindustrial, proponiendo entonces hablar de "reemplazo" en lugar de desplazamiento (postulado que desencadenaría la famosa polémica con Slater, 2009). Más allá de cualquier porfía sobre la posible función que podría cumplir el crecimiento de las clases medias en estos procesos, resulta imprescindible considerar cómo determinadas zonas cambian su estatus relativo respecto del conjunto de la ciudad.

Una lógica similar a la que Hammet sigue es la del trabajo de Sabatini, Rasse, Cáceres, Sarella, Trebilcock (2017), quienes, ante la imposibilidad de utilizar los datos del inconsistente censo chileno de 2012, ${ }^{1}$ identifican proyectos de desarrollo inmobiliario con precios orientados a grupos medios o altos en distritos que en un momento previo (2002) tenían un carácter sociodemográfico popular, y luego desarrollan un trabajo de campo complementario. Aunque la solución es ingeniosa, la identificación de gentrificación termina siendo muy sensible al tamaño de la unidad espacial seleccionada. Así, la construcción de un nuevo barrio de clase media en un distrito predominantemente popular sería interpretada como gentrificación, aunque se desarrollara sobre terrenos baldíos o con usos no residenciales. Un obstáculo similar aparece en otros trabajos, como el de Silva (2013), que utiliza la Encuesta Anual de Hogares de la CABA entre 2003 y 2011 para valorar si las políticas de regeneración urbana habían tenido como consecuencia la gentrificación de la zona sur de la ciudad. El bajo nivel de desagregación de los datos permitido por esta fuente podría ser una de las

${ }^{1}$ Sobre los problemas técnicos del censo chileno de 2012, puede consultarse INE, 2014. 
razones por las que el autor no encontraba cambios significativos, potencialmente identificables con mayor nivel de detalle.

Por lo expuesto hasta aquí, consideramos que un indicador de gentrificación podría aprovechar la complementariedad de una variable relativa al incremento del estatus social y de otra vinculada a la mejora de las condiciones de habitabilidad, a la vez que necesitaría presentar un nivel de desagregación suficiente para detectar cambios significativos. Además, estos datos deberían analizarse no sólo desde sus saldos brutos por microunidades espaciales, sino también a la luz del comportamiento urbano general en el periodo intercensal (Díaz Parra, 2016); es decir, analizando la gentrificación no sólo como un cambio de un sector a lo largo del tiempo, sino como un cambio en relación al conjunto de la ciudad.

\section{Desarrollo metodológico}

La metodología constó de dos etapas: una primera parte, más extensa, centrada en la identificación de sectores de la CABA que podrían haber sufrido procesos de gentrificación; y una segunda parte, focalizada en el análisis sociodemográfico de dos de estos sectores, orientada a caracterizar algunos aspectos del proceso y a identificar las características que los habrían hecho "gentrificables".

Respecto de la primera parte, la identificación del proceso se realizaría a partir de dos indicadores - que llamaremos indicadores guía-, uno de estatus y otro habitacional.

Dado que el censo argentino carece de variables sobre condición sociolaboral o de ingresos que permitan una comparación intercensal a un nivel suficiente de desagregación, se optó por utilizar una variable relacionada: el peso del nivel educacional superior (porcentaje de población $\geq 20$ años de edad con estudios universitarios o posuniversitarios completos). El indicador del nivel educacional presenta varias ventajas. La principal es que al día de hoy esta variable (y en particular el peso de la población de estudios superiores) encuentra una fuerte correlación con otras variables de estatus, como pueden ser el tipo de ocupación y el nivel de renta (Galassi y Andrada, 2011), y por ende, también con la distribución del precio de la vivienda y alquiler. Además, esta correlación se produce en gran parte de los censos en Latinoamérica (y fuera de la región), lo que, unido a su aparición frecuente en los censos (en distintos países y en distintas fechas), la convierte en una variable imprescindible para identificar los cambios en el estatus. 
En cuanto al indicador habitacional, se eligió trabajar con el hacinamiento (porcentaje de hogares con tres o más personas por cuarto). Los censos utilizados (2001 y 2010) no proporcionan información adecuada sobre el estado de la edificación o sobre el precio del metro cuadrado, alternativas que hubieran resultado interesantes. Esto supone el inconveniente de no poder contar con un indicador de la inversión en el parque residencial. De todas maneras, a nivel teórico, si la variable de la proporción de universitarios nos indica el peso de las clases medias, el hacinamiento incluye la dimensión de la habitabilidad (en concreto, la relación entre tamaño del hogar y la vivienda), y ha demostrado una capacidad histórica para dar cuenta de los cambios sociohabitacionales en la ciudad, identificando el peso de estratos sociales bajos, que en el contexto porteño están históricamente vinculados a este tipo de precariedad habitacional (Torres, 1978, 2001, 2006).

Los indicadores guía sobre gentrificación serían entonces la variación intercensal (2001-2010) de estas variables a nivel de radio censal, ${ }^{2}$ a la luz de su comportamiento y evolución general dentro del conjunto de la ciudad (i. e., considerando la tendencia general urbana hacia el incremento del porcentaje de universitarios o hacia la baja gradual de los niveles de hacinamiento).

Lógicamente, se descartaron aquellos radios ubicados en 2001 por encima de la media de la ciudad en ambos indicadores, ya que deberían entenderse como zonas en las que la situación sociorresidencial de partida era buena. Por supuesto, esto conlleva la limitación de descartar zonas que podrían haberse gentrificado en momentos previos (i. e., antes del censo de 2001), o encontrarse en una fase avanzada de este proceso. Cabe remarcar nuevamente que la metodología propuesta se restringe exclusivamente a identificar áreas que podrían haber sufrido una gentrificación relativa, siendo todavía predominantemente populares en 2001. La triangulación de los resultados con la bibliografía podría sugerir la necesidad de ampliar el análisis a otros censos (e. g., 1991), donde sería factible identificar otros sectores descartados en el actual experimento.

Posteriormente, se debió enfrentar el conocido problema de la unidad espacial modificable, asociado a la no correspondencia espacial de los radios censales de 2001 y 2010. Esto se debe a que a partir de la sanción de la Ley de Comunas en 2005 (que genera una nueva jurisdicción de segundo orden en la ciudad), los límites de los radios fueron redefinidos y reclasificados para el censo de 2010, por lo que prácticamente no existen unidades promedio.

${ }^{2}$ Unidad territorial de máximo detalle en el censo argentino, con unas 300 viviendas en 
espaciales coincidentes entre ambos censos. Teniendo en mente esta dificultad y buscando mantener el máximo nivel de desagregación, se desarrolló la siguiente estrategia:

a) En primer lugar se representaron cartográficamente los dos indicadores guía (universitarios y hacinamiento) por radio censal, organizando los resultados en 11 categorías que siguen percentiles de distribución según desvíos en torno a la media, de manera que cada una concentre $9.09 \%$ de la distribución Z. De esta manera, la categoría 1 representa los valores más desfavorables (mayor porcentaje de hacinamiento o menor porcentaje de universitarios), la 11 representa los valores más favorables (menor porcentaje de hacinamiento o mayor porcentaje de universitarios), al tiempo que la categoría 6 engloba la horquilla de valores en torno a la media.

b) En segundo lugar, las variables se compararon en su evolución 20012010, pero ahora sólo en tres grupos: radios en torno a la media de la distribución de la ciudad (i. e., horquilla central), radios significativamente por debajo de la media (categorías 1 a 5) y radios significativamente por arriba de la media (categorías 7 a 11). El resultado de la comparación cartográfica intercensal permite entonces identificar conglomerados de radios que se encontraban significativamente por debajo de la media en 2001, pero pasaban a ubicarse significativamente por encima de la media en 2010.

c) En tercer lugar, al conjunto de radios que cambian su posición relativa en el periodo estudiado se le aplicaron indicadores locales de autocorrelación espacial, identificando la existencia de clústeres de este tipo de radios con menos de $5 \%$ de posibilidades de ser resultado de una distribución aleatoria. ${ }^{3}$

d) Finalmente, se identificaron zonas donde se solapaban los clústeres significativos de radios que cambiaban su posición relativa para cada uno de los dos indicadores guía utilizados.

Se utilizaron tareas de campo y el cruce de la información con fuentes secundarias para ajustar la delimitación de los conglomerados 2001 y 2010, de manera que coincida con unidades espaciales significativas para la sociedad urbana en que se está trabajando: estos son barrios $-\mathrm{u}$ otros sectores-

\footnotetext{
${ }^{3}$ Esta operación se desarrolló utilizando el programa Geoda (spatial.uchicago.edu/ software) sobre la cartografía censal de 2010, que es sobre la que se identificaron los radios que cambiaban su posición relativa. Existen numerosos artículos científicos que explican el funcionamiento de la I de Moran y de los indicadores locales de autocorrelación espacial. Son especialmente recomendables los trabajos de Luc Anselin, quien ha desarrollado un trabajo notable sobre estas cuestiones en las dos últimas décadas (Anselin y Rey, 2009).
} 
típicamente identificables por los agentes de la producción y del consumo de espacio. En otras palabras, se delimitaron mosaicos de radios censales coincidentes con barrios o zonas socialmente reconocidos. Así, al trabajar sobre unidades espaciales mayores, que agrupan entre 20 y 50 radios por censo, los mosaicos de radios censales, a pesar de no ser espacialmente idénticos, se tornan altamente comparables.

Una vez delimitados estos mosaicos, se comparó el comportamiento de los dos indicadores guía de gentrificación, a la luz de la evolución de los mismos para el conjunto de la ciudad, lo que permite valorar la mayor o menor intensidad de los cambios en estos distintos sectores.

Posteriormente, se pasó a la segunda parte del trabajo, donde se realizó un análisis estadístico pormenorizado de dos de estos sectores (San Telmo y Palermo Soho), estructurado analíticamente en dos etapas: a) análisis en el momento cero (2001) para buscar pistas sobre posibles características que podrían haber tornado más "gentrificable" a esta zona, y b) análisis en el momento de cierre (2010), para ayudar a caracterizar los componentes sociales, habitacionales y locativos asociados a los procesos de gentrificación en curso.

Las variables para el análisis pormenorizado 2001-2010 fueron los porcentajes de: población de Bolivia, Paraguay y Perú; ${ }^{4}$ población de Europa Occidental, Estados Unidos, Canadá, Japón y Australia; desempleados; población mayor de 65 años; hogares con un miembro; hogares con seis o más miembros; hogares inquilinos; hogares en piezas de inquilinato, en piezas de hotel pensión, en viviendas móviles y en situación de calle; ${ }^{5}$ viviendas vacías.

Puede observarse que para analizar la gentrificabilidad se cuenta con variables que responden a características señaladas en trabajos previos: vulnerabilidad y estatus bajo de la población y existencia de predios vacantes. Naturalmente, existen otras variables clave de la gentrificabilidad que, por centrarse el presente trabajo en los censos de población, se han dejado de lado; entre ellas podrían destacarse la proximidad a áreas centrales o sectores de estatus alto y los precios del suelo preexistentes.

De manera similar, las variables del censo de 2010 en estos sectores podrían ayudar a identificar rasgos particulares presentes en los procesos concretos de gentrificación, respecto del perfil de los nuevos habitantes. Por ejemplo, la gentrificación puede tener una incidencia diversa respecto de la densidad de población; así, el porcentaje de mayores de 65 años o el

\footnotetext{
${ }^{4}$ Perfil de inmigración sumamente influyente dentro de la CABA, a la vez que de altos niveles de vulnerabilidad.

${ }^{5}$ En este punto se optó por excluir las viviendas tipo casilla, ya que las mismas presentan una fuerte concentración dentro de las villas (asentamientos informales centrales) de la ciudad, hecho que hubiera generado un sesgo estadístico notable.
} 
tamaño de los hogares permitirían conocer cómo ha influido el proceso en la estructura por edades y de los hogares. Respecto del tipo de viviendas, permite cotejar los datos con relación al porcentaje de inquilinos, viviendas particulares desocupadas y viviendas vacías. Finalmente, en algunos casos podría resultar relevante comprobar cómo ha afectado la gentrificación a la estructura por nacionalidades, utilizando tanto el porcentaje de población migrante vulnerable, como la población de la Unión Europea, Estados Unidos, etc., que podría corresponderse con cierta gentrificación transnacional (Sigler y Wachsmuth, 2015).

\section{Identificación de sectores con indicios de gentrificación}

Los dos indicadores guía de gentrificación han mostrado una fuerte autocorrelación espacial. La variable de estatus arrojaba un índice de Moran de 0.88 en 2001 y de 0.87 en 2010 , y la variable de habitabilidad de 0.56 en 2001 y de 0.72 en 2010 . Esto da cuenta de una fuerte tendencia a la concentración espacial de los valores altos y bajos de estatus permanente en el tiempo y una tendencia a la concentración espacial creciente en el tiempo en el caso del indicador de habitabilidad.

Los Mapas 1 y 2 ofrecen la representación cartográfica de la evolución 2001-2010 de los dos indicadores guía, a partir de los 11 percentiles de desvíos respecto a la media. Esta secuencia permite identificar grandes conglomerados de radios de valores altos y bajos para ambos indicadores, que coinciden a grandes rasgos con los macrosectores privilegiados y empobrecidos de la ciudad.

Puede observarse que, más allá de ciertos cambios tendientes a la expansión de las zonas "buenas", la evolución no muestra cambios dramáti$\cos$, apareciendo grandes áreas estables de valores altos y bajos que parecen permanecer invariantes a lo largo del tiempo. Asimismo, la cartografía confirma a simple vista que el indicador de estatus presenta un grado de autocorrelación espacial mayor que el de habitabilidad, de distribución algo más dispersa y fragmentada.

Al analizar la representación cartográfica de los dos indicadores (Mapa 1), aparece claramente dibujado el corredor Norte, donde se localizan los barrios más ricos de la ciudad y las dos principales macroislas de valores altos en el centro geográfico de la CABA (aproximadamente coincidente con el barrio de Caballito) y en el extremo oeste (aproximadamente concuerda con Villa Devoto, Villa del Parque y, en menor medida, con Villa Urquiza). En sentido inverso, se identifica también de forma clara el corredor Sur de 
barrios pobres que, partiendo del propio centro de la ciudad, se extiende a lo largo del Riachuelo, a la vez que se suman otros conglomerados más pequeños, ubicados en las zonas de Once y Paternal-Chacarita.

\section{Mapa 1}

Universitarios según radio censal, 2001 y 2010
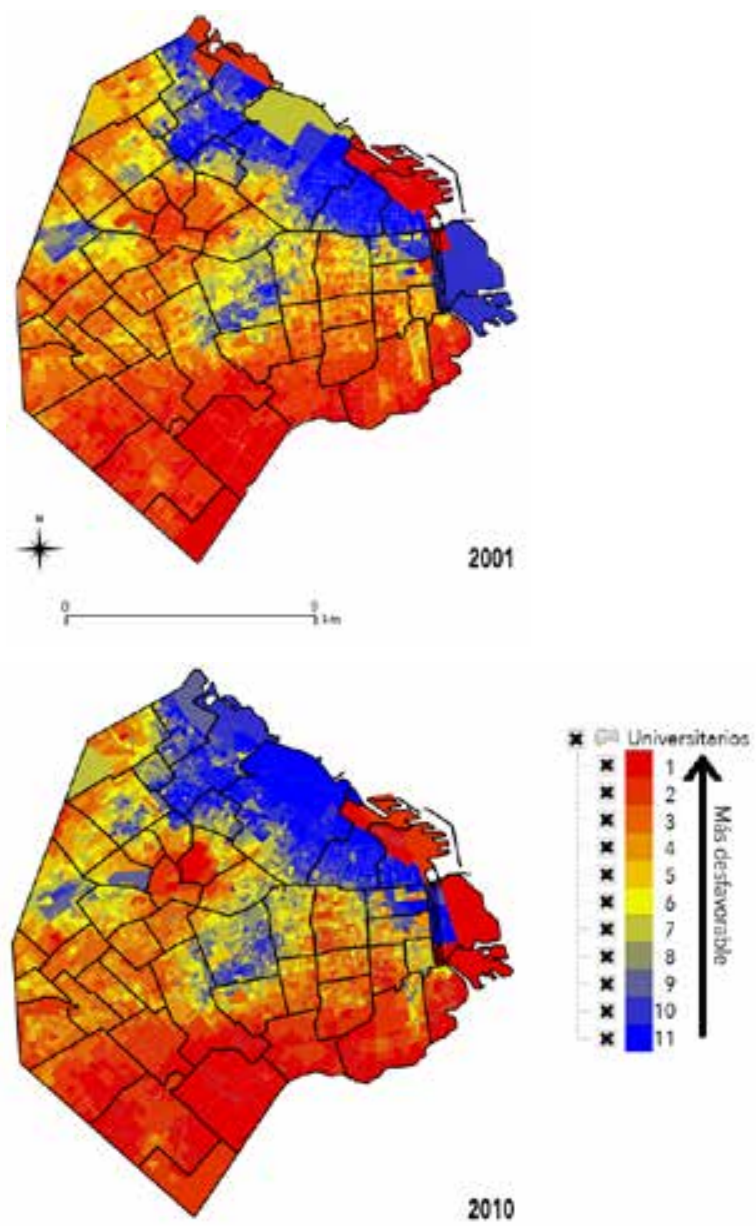

Fuente: Elaboración propia con base en INDEC, 2001 y 2010. 


\section{Mapa 2}

Hacinamiento según radio censal, 2001 y 2010
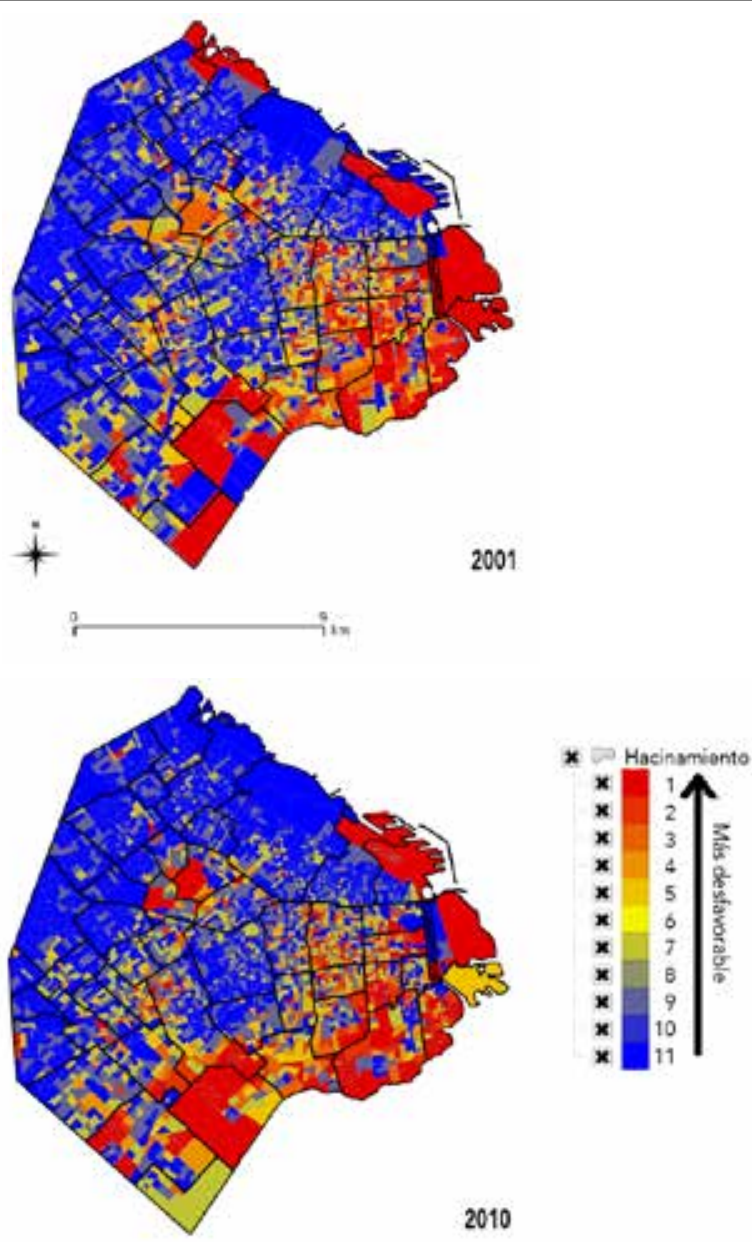

Fuente: Elaboración propia con base en INDEC, 2001 y 2010.

Ahora bien, más allá de esta zonificación general en zonas "buenas" y "malas" estables a lo largo del tiempo, la variación intercensal de detalle en los dos indicadores guía también sirve para identificar las zonas específicas donde los cambios indicarían procesos de gentrificación. En el Mapa 3 se 
representan en verde [gris medio en la impresión sin color] las zonas que en 2001 se ubicaban en la categoría 6 (horquilla central) o en las categorías 7 a 11 (sensiblemente por encima de la media), ya que -siguiendo nuestros postulados teóricos- no podrían de partida considerarse "gentrificables" por ser zonas "buenas" o en torno a la media. También se grafican en verde las zonas que en 2001 se ubicaban sensiblemente por debajo de la media (categorías 1 a 5), pero sólo cambiaban a la horquilla central en 2010 (es decir un cambio no del todo significativo). Por su parte, en rojo [gris obscuro en la impresión sin color) se representan las zonas que tanto en 2001 como en 2010 se ubicaban sensiblemente por debajo de la media (zonas "malas", que no cambian). Por último, se representan en amarillo (gris claro en la impresión sin color) aquellos radios censales que en 2001 estaban sensiblemente por debajo de la media y en 2010 pasaban a estar sensiblemente por encima (i. e., nuestras zonas de interés).

Los datos recogidos permiten una serie de observaciones. En primer lugar, respecto del indicador de estatus, es notorio que los radios con indicios de gentrificación se ubican principalmente en sectores colindantes al corredor Norte y a las dos macroislas mencionadas, de buena situación ya en 2001. Además de esta pauta, fronteriza y dispersa, puede identificarse la conformación de varios conglomerados "buenos" de cierta relevancia. En conjunto, estos cambios dibujan una tendencia en la cual las macroislas de estatus elevado y el cono de altos ingresos parecen tender a fusionarse en un continuo, dejando una zona de bajo estatus, definida cada vez más en forma de isla entre Paternal y Chacarita, además del surgimiento de un conglomerado de estatus alto en el centro sur de la ciudad, que ha tenido tradicionalmente un carácter popular.

En cuanto al indicador de habitabilidad, los radios que mejoran su posición relativa se encuentran mucho más dispersos; aun así, es reconocible que las mejoras se localizan por lo general fuera de las zonas estables de alto y bajo estatus y más próximas al centro de la ciudad.

Sin embargo, tal cual se analizó en el marco teórico, los cambios ascendentes en las variables de estatus socioeducativo o habitacional pueden deberse a muy variadas razones. Por ello, es necesario avanzar en un análisis integrado entre ambos indicadores guías. Como se mencionó, sobre la distribución de los radios con indicios de gentrificación se aplicaron los indicadores locales de autocorrelación espacial, que permiten reconocer clústeres estadísticamente significativos de estas unidades censales, descartando que fuesen fruto de una distribución aleatoria. 


\section{Mapa 3}

Universitarios y hacinamiento, según evolución, 2001-2010
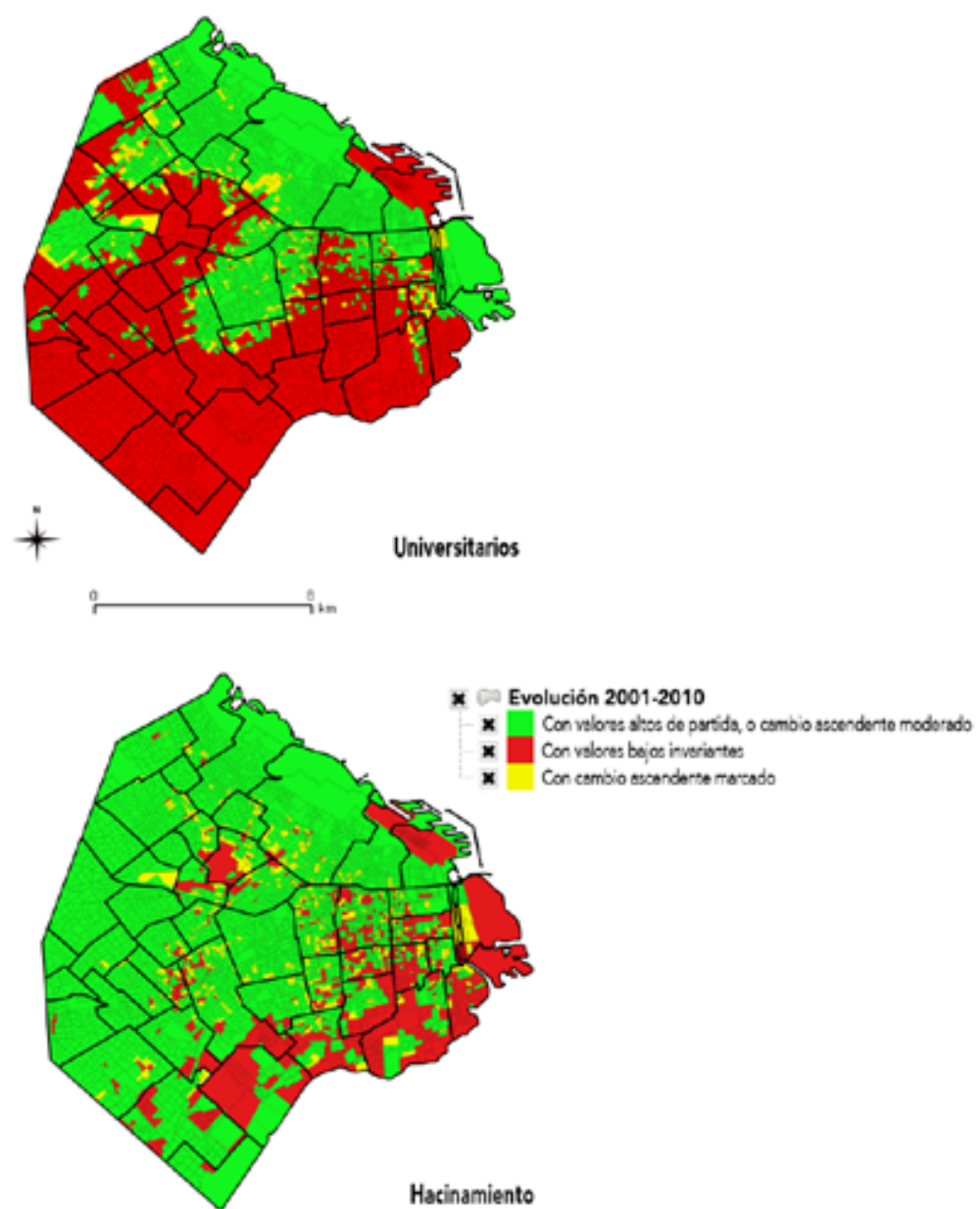

Fuente: Elaboración propia con base en INDEC, 2001 y 2010.

Como resultado, se identificaron varios conglomerados significativos para el indicador de estatus, principalmente distribuidos en torno a las zonas limítrofes con los clústeres tradicionales de estatus elevado, con la excep- 
ción notoria del barrio de San Telmo y el sector oriental de Barracas, ubicados en el sur tradicionalmente popular. Al realizar la misma operación con los resultados del indicador de habitabilidad y comparar ambos indicadores, quedaron dos grandes conglomerados: el primero está ubicado en la zona inmobiliaria conocida como Palermo Soho, más algunas zonas limítrofes, como el norte del barrio de Chacarita (también conocido como Chacalermo); el segundo coincidiría con el barrio de San Telmo y una prolongación hacia el sur sobre parte del barrio de Barracas (zona conocida como Barracas Noreste).

Contrastando esta información con la bibliografía existente sobre la historia urbana y la reestructuración reciente de la ciudad, se identificaron en cada uno de estos dos conglomerados dos subsectores, barrios con cierta identidad de cara a los agentes de la producción y el consumo, como zonas óptimas para un análisis en profundidad (véase el Mapa 4). Estos subsectores se han delimitado de una manera abarcativa (mosaicos), es decir, considerando no sólo los radios específicos con evidencia de gentrificación, sino también los radios contiguos circundantes. Esto no sólo permite reconstruir unidades urbanas con "identidad inmobiliaria" real, sino también reducir drásticamente el ya mencionado problema de la "unidad espacial modificable", ya que, al trabajar sobre agregados mayores, los desfasajes producidos por el cambio en la forma de los radios se minimizan, habilitando comparaciones aceptables. ${ }^{6}$

En base a la metodología empleada, varios sectores en los que sería esperable identificar gentrificación en el periodo intercensal analizado, no muestran cambios significativos asociables con este proceso. En estas zonas podría descartarse gentrificación hasta el año 2010 aunque, claro está, no por ello debería descartarse que el proceso sea detectado al considerar el siguiente censo en 2020. Un ejemplo es el Abasto (Carmán, 2006), donde se ha registrado renovación urbana reciente. También Parque Patricios y La Boca -reconocidas por muchos académicos como algunas de las áreas de renovación urbana más intensa del sur popular de la ciudad (Díaz, Fermé y Raspall, 2010; Socoloff, Colombo, Kitay, Maltz, Raullansky, Seia, Stiberman y Urdampilleta, 2013; Apaolaza, Blanco, Lerena, López-Morales, Lukas y Rivera, 2016; Lerena, 2016; Goicoechea, 2017)- seguían encontrándose en su totalidad por debajo de la media para los indicadores utilizados.

${ }^{6}$ La correspondencia espacial entre los agregados de radios de 2001 y 2010 tiene: San Telmo, 86.6\%; Barracas Norte, 88.4\%; Palermo Soho, 97.6\%; y Chacalermo, 98.2\%. 


\section{Mapa 4}

Identificación de indicios de gentrificación, 2001-2010

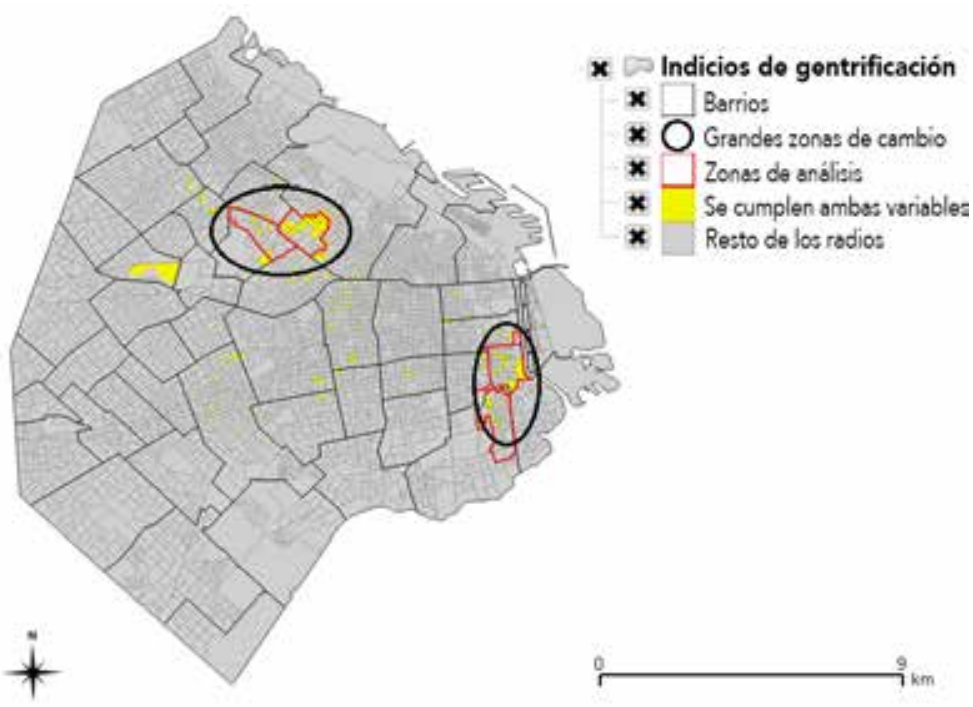

Fuente: Elaboración propia con base en INDEC, 2001 y 2010.

De igual modo, el conglomerado de Villa Urquiza no parece adecuado para hablar de gentrificación, no sólo por la presencia de una isla de alto estatus en el centro de esta zona -estable al menos durante el periodo elegido-, sino fundamentalmente por la ausencia de radios con una mala situación de habitabilidad en el año 2001. Contrariamente, las mejoras en la habitabilidad de extensas zonas entre Balvanera-Boedo, y entre Flores- Floresta no vienen acompañadas por un conglomerado significativo de radios donde haya un cambio positivo de estatus.

Los cuatro grandes conglomerados identificados con indicios de gentrificación, según la metodología desarrollada, coinciden con buena parte de la bibliografía científica sobre el desarrollo urbano de la urbe. Los barrios de San Telmo y Barracas forman parte de los sectores en el centro sur de la ciudad donde se ha concentrado la mayor parte de la inversión pública desde la década de los noventa, en gran medida orientada a provocar procesos de renovación urbana (Herzer, 2008). Mientras, Palermo Soho y algunos sectores limítrofes han sufrido una conocida valorización como zona residencial de estatus alto y enclave comercial y de ocio nocturno (Carbajal, 2003). 
En el Cuadro 1 se presentan los valores 2001 y 2010 de los dos indicadores guía de gentrificación para cada uno de los cuatro sectores delimitados, así como para el conjunto de la CABA.

\section{Cuadro 1}

Valores indicadores guía en sectores con indicios de gentrificación

\begin{tabular}{lccc}
\hline Jurisdicción & Censo & Universitarios \% & Hacinamiento \% \\
\hline Total CABA & 2001 & 10.74 & 1.57 \\
& 2010 & 14.37 & 1.54 \\
& $\Delta 2001-2010$ & +3.63 & -0.03 \\
\hline Barracas Noreste & 2001 & 8.99 & 1.79 \\
& 2010 & 15.01 & 1.15 \\
& $\Delta 2001-2010$ & +6.02 & -0.64 \\
\hline Chacalermo & 2001 & 8.88 & 1.74 \\
& 2010 & 16.23 & 1.17 \\
& $\Delta 2001-2010$ & +7.35 & -0.57 \\
\hline Palermo Soho & 2001 & 9.91 & 2.25 \\
& 2010 & 20.67 & 0.81 \\
& $\Delta 2001-2010$ & +10.76 & -1.44 \\
\hline San Telmo & 2001 & 8.67 & 3.10 \\
& 2010 & 15.99 & 1.73 \\
& $\Delta 2001-2010$ & +7.32 & -1.37 \\
\hline
\end{tabular}

Fuente: Elaboración propia con base en INDEC, 2001 y 2010.

Como se anticipaba, los cuatro sectores mejoran significativamente su posición relativa respecto del total de la ciudad en el periodo intercensal y para los dos indicadores guía. En 2001 tenían un peso de población universitaria y un nivel de hacinamiento por debajo y por encima del conjunto de la ciudad, respectivamente. Sin embargo, esta situación se invierte en 2010, en algunos casos de forma más significativa que en otros. Las zonas de Chacalermo y Palermo Soho muestran un cambio más espectacular, pero también eran sectores que partían de una situación mejor, algo más próxima a la media. En las zonas de Barracas Noreste y San Telmo la mejora es más sutil, pero partían de una situación relativamente peor en 2001. Se da el caso de que el indicador sociohabitacional para San Telmo es el único que no pasa a estar por debajo de la media de la ciudad; sin embargo, se trataba también del peor dato de habitabilidad de todo el cuadro en 2001. Valorando los dos 
indicadores en conjunto, los dos barrios que arrojarían los resultados más contundentes serían los de San Telmo y Palermo Soho, que serán estudiados en profundidad a continuación.

\section{Exploración pormenorizada del caso de San Telmo y Palermo Soho}

San Telmo es una unidad delimitada oficialmente, además del centro histórico declarado de la ciudad de Buenos Aires. Palermo, por su lado, es una unidad administrativa de enormes dimensiones, con un origen histórico en torno a 1900, dentro del cual el subsector Palermo Soho cuenta con una identidad muy marcada. Coincidiendo con el antiguo barrio de Palermo Viejo, sería renombrado como Palermo Soho a partir de su revitalización económica y residencial desde la década de los noventa. En estos dos casos, los indicadores guía ofrecen los indicios más sólidos de que en el periodo intercensal 2001-2010 se ha producido un proceso de gentrificación, tal cual ha sido definido en el marco teórico.

El Cuadro 2 ofrece variables censales significativas para analizar posibles elementos que inciden en la gentrificabilidad del caso en el año cero del estudio (2001), así como otras que podrían caracterizar el proceso de transformación sociodemográfica hacia 2010.

A nivel sociodemográfico, la gentrificabilidad puede estar vinculada a una mayor susceptibilidad al desplazamiento de la población de bajos recursos o a algunas características del parque de viviendas que faciliten la entrada de nueva población. No obstante, al compararlos con el dato del conjunto de la ciudad, la mayor parte de los indicadores de vulnerabilidad de población no resultan significativos. San Telmo contaba en 2001 con un envejecimiento próximo al del conjunto de la ciudad y un dato similar de población extranjera procedente de Paraguay, Perú y Bolivia, mientras el dato de desempleo y de hogares con más de seis miembros eran considerablemente inferiores a los del conjunto de la urbe. Estos dos últimos datos sí eran algo superiores en Palermo Soho, sin llegar a suponer una desviación demasiado notable con respecto al dato del conjunto de la ciudad. Sí resulta más significativo el dato del porcentaje de personas que viven en viviendas inadecuadas (inquilinatos, pensiones, móviles y situación de calle), cuatro puntos y medio superior a la media urbana en Palermo Soho y casi diez puntos más alto en San Telmo. Por supuesto, el descenso de este dato en el periodo intercensal ha sido enorme en los dos casos de estudio. 


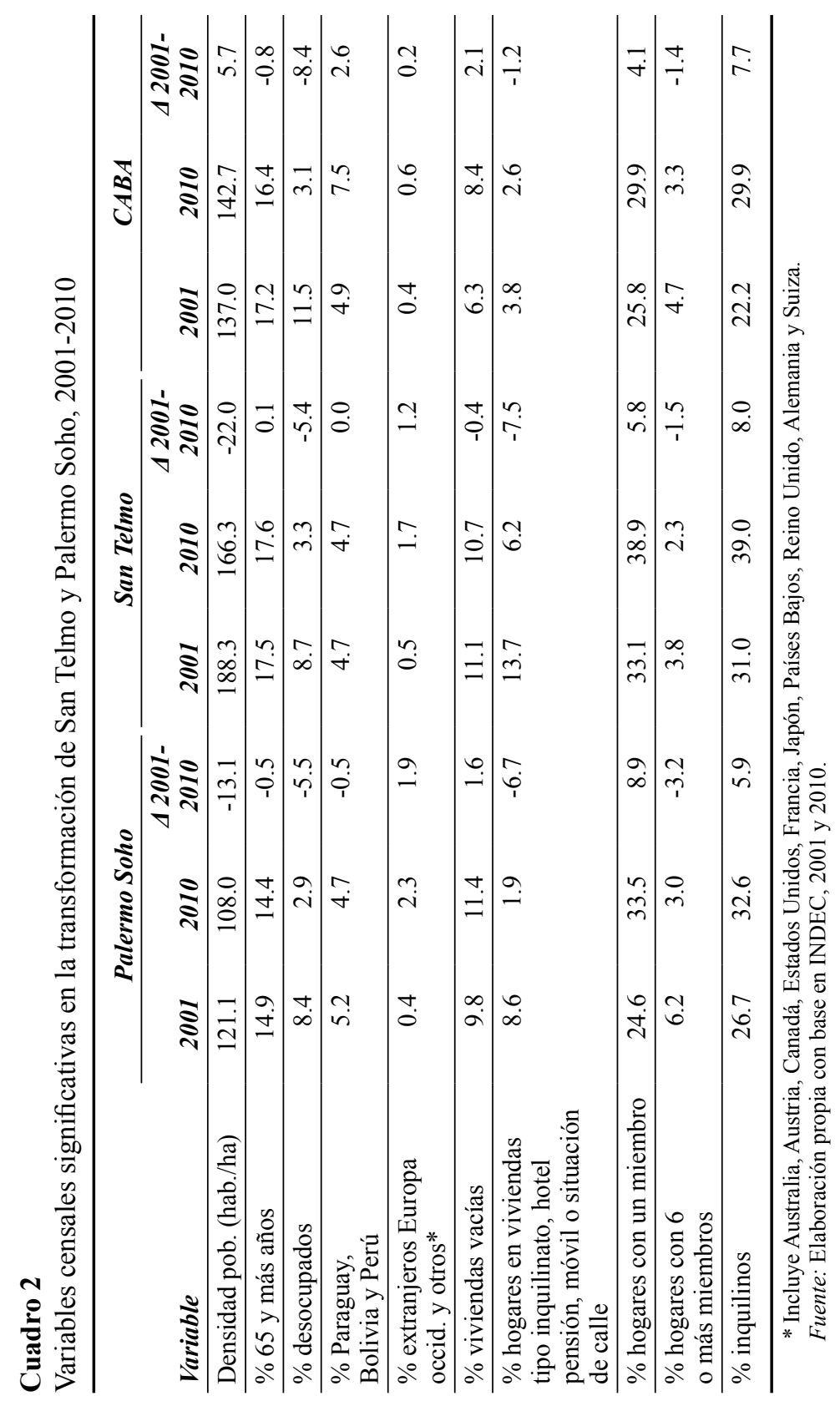


En términos generales, parecen ser mucho más significativos los valores referidos a la vivienda que aquellos relativos a grupos sociodemográficos particulares. Así, junto con el llamativo guarismo de los tipos de vivienda vulnerable, otros valores en los que los dos casos se desviaban notablemente del conjunto de la ciudad eran los del régimen de tenencia y de viviendas vacantes. Ambos sectores contaban en 2001 con una proporción de viviendas vacías y un porcentaje de inquilinos muy elevados, siendo este último, además, un dato que se ha incrementado también notablemente en ambos casos en el periodo intercensal. Este dato está directamente relacionado con un mayor dinamismo de los hogares a la hora de cambiar de residencia. El elevado valor de hogares unipersonales puede tener una interpretación mucho más ambigua, aunque en relación a las otras dos variables podría indicar también una mayor capacidad de movilidad de la población residente. El porcentaje de hogares con más de seis miembros también se reduce de manera relativa en estos sectores.

La variación de los valores en el periodo intercensal ofrece otra pista importante sobre las transformaciones acaecidas en el sector. Mientras que la $\mathrm{CABA}$ en su conjunto tiende a densificarse aumentando significativamente su población, tanto San Telmo como Palermo Soho pierden población en este periodo, disminuyendo la densidad en 22 y 13 puntos porcentuales, respectivamente. Este dato, sumado al enorme incremento relativo de la población con estudios universitarios, permite descartar que el aumento relativo del estatus del sector se debiese a una simple repoblación por parte de la clase media. De forma paralela a la entrada de este grupo, ha debido darse forzosamente la salida de otra población, no universitaria, lo que explicaría el enorme incremento del indicador. Es más, esto también podría desmentir la afirmación común referida a la capacidad de los planes de revitalización de revertir las tendencias a la pérdida de habitantes.

Otro elemento de interés es la población paraguaya, boliviana y peruana, que en el periodo intercensal se incrementa muy notoriamente en la ciudad, pero aparece estancada en San Telmo y disminuye ligeramente en Palermo Soho. Esto puede interpretarse como una exclusión lógica de este perfil de inmigración dentro del grupo que está entrando en la zona durante el periodo intercensal. Por el contrario, el peso de las personas nacidas en Europa occidental y otros países ricos, que en 2001 era similar en el conjunto de la CABA, en los casos de estudio observa un aumento relativo notable, triplicando el peso que este mismo grupo tiene en el conjunto de la ciudad hacia el final del periodo.

De esta forma, los datos que podemos extraer del censo indican que los nuevos vecinos en San Telmo y Palermo Soho tenderían a ser un grupo que 
conforma hogares de reducido tamaño, con nivel de formación elevada, sin ser un grupo lo suficientemente joven como para reducir de forma notoria el dato de envejecimiento, y con un componente de población extranjera procedente de países ricos sensiblemente por encima del promedio de la ciudad. A costa de la entrada de este grupo, tienden a reducirse otros perfiles, saldrían hogares de gran tamaño, con elevado nivel de hacinamiento, jóvenes, y habitando en viviendas típicamente vulnerables de la ciudad central, como son los inquilinatos y los hoteles-pensión.

\section{Conclusiones}

La búsqueda de evidencias cuantitativas de este tipo de fenómenos de transformación socioespacial no sustituye la reflexión teórica sobre los mecanismos que los producen, ni aquellas aproximaciones que utilizan enfoques cualitativos o que se centran en los precios del suelo como expresión de la renta de suelo. Por el contrario, supone una contribución más, a nuestro juicio clave en la actualidad, a la hora de respaldar la preocupación por las injusticias socioespaciales y justificar la intervención política sobre las mismas, interviniendo en el debate sobre la gentrificación en favor de las perspectivas críticas.

En ese sentido, la metodología empleada muestra cierta capacidad para identificar la existencia de gentrificación, partiendo de una descripción muy definida del fenómeno como la aquí ofrecida. Así, se ha mostrado cómo esta estrategia puede ser de utilidad a la hora de falsar la hipótesis de gentrificación como sustitución de población frente a diversas hipótesis nulas: la identificación de estos procesos como mera expresión de cambios en la estructura social, como incrementos de la población o residencialización o como asentamiento de clases medias que no implica desplazamiento. Por otro lado, puede servir de base para guiar estudios de caso a zonas concretas y a grupos sociales particulares, permitiendo formular hipótesis que necesariamente requerirían de otro tipo de datos complementarios.

El actual trabajo podría ampliarse incluyendo otros censos, lo que podría resultar muy clarificador para observar más claramente las tendencias de cambio de los patrones de segregación socioespacial de la ciudad. Indudablemente, el censo de 2020 aportará información muy valiosa, pero la inclusión del censo de 1991 también podría arrojar mayor claridad y respaldar las tendencias observadas en el presente trabajo. Otra forma de expandir esta investigación sobre el caso de Buenos Aires sería incluir el cono urbano de la ciudad (conjunto del área metropolitana), lo que ofrecería toda 
una serie de retos adicionales respecto del tipo de unidades adecuadas para integrar la investigación de la CABA y su periferia.

Como se ha indicado, hay valiosos estudios de caso que indican la existencia de procesos similares en sectores que las variables utilizadas no encuentran significativos para el periodo estudiado. La observación sobre el terreno parece seguir siendo indispensable en este sentido, así como el recurso a otros datos no recogidos actualmente en los censos, como los precios del suelo o el factor de la localización geográfica relativa.

Asimismo, la cuestión de la detección de fases tempranas o de la sensibilidad a estos fenómenos, lo que denominamos gentrificabilidad, parece limitada dentro de una estrategia centrada exclusivamente en los censos. En cualquier caso, permite confirmar la relevancia de algunas variables como factores de la gentrificación, especialmente aquellas relacionadas con la mayor movilidad residencial potencial o con la existencia de stocks disponibles para ser transformados en vivienda.

Finalmente, está la cuestión de la comparabilidad entre distintas ciudades. Podría ser relativamente sencillo comparar diversas urbes argentinas siguiendo estrictamente la metodología expuesta. Por otro lado, a la hora de comparar distintos censos nacionales, podrían aplicarse las líneas generales de la estrategia que hemos utilizado, pero teniendo en cuenta las particularidades de cada censo y de cada región, que probablemente obliguen a seleccionar otras variables como indicadores. Además, si bien algunas de las limitaciones encontradas en este trabajo (principalmente el problema de la unidad espacial modificable) no se encuentran en otros censos nacionales, o incluso en otras ciudades argentinas, es esperable encontrar otra serie de obstáculos. En este sentido, se deberían examinar las potencialidades y limitaciones de cada censo nacional para realizar comparaciones entre distintas ciudades latinoamericanas en el futuro.

\section{Bibliografía}

Alexandri, G., González, S. y Hodkinson, S. (2016). Geografías del desplazamiento en el urbanismo de América Latina. Revista INVI, 31(88), 9-25. Recuperado de http://www.revistainvi.uchile.cl/index.php/INVI/ article/view/1176/1310

Anselin, L. y Rey, S. (2009). Perspectives on spatial data analysis. Nueva York, NY: Springer.

Apaolaza, R. (2018). Territorio, transporte y capitales. Dinámicas y efectos del aislamiento socioterritorial sobre los jóvenes residentes de los 
nuevos asentamientos periféricos del Área Metropolitana de Buenos Aires (Tesis doctoral, Universidad de Buenos Aires, Facultad de Filosofía y Letras). Recuperado de http://repositorio.filo.uba.ar/handle/ filodigital $/ 4586$

Apaolaza, R., Blanco, J., Lerena, N., López-Morales, E., Lukas, M. y Rivera, M. (2016). Transporte, desigualdad social y capital espacial: análisis comparativo de Buenos Aires y Santiago de Chile. Íconos. Revista de Ciencias Sociales, 56, 19-41. Recuperado de http://revistas.flacsoandes. edu.ec/iconos/article/view/2148

Apaolaza, R. y Bosoer, L. (2014). Identificación de procesos de gentrificación a partir del análisis estadístico espacial de micro-unidades censales: una propuesta para el caso de la Ciudad de Buenos Aires. Ponencia presentada en el II Seminario Internacional "Contested Cities", Universidad de Chile, Facultad de Arquitectura y Urbanismo. Santiago de Chile, 8 y 9 de abril.

Bates, L. (2013). Gentrification and displacement study. Portland, OR: BPS. Blanco, J. y Apaolaza, R. (2016). Políticas y geografías del desplazamiento. Contextos y usos conceptuales para el debate sobre gentrificación. Revista INVI, 31(88), 73-98. Recuperado de http://www.revistainvi.uchile. cl/index.php/INVI/article/view/1085

Blanco, J., Apaolaza, R. y Lerena, N. (2015). Gentrificación, movilidad y capital espacial: una exploración del barrio de Parque Patricios, Buenos Aires. Conferencia Anual COES 2015 "Conflictos urbanos y territoriales: ¿desafiando la cohesión social?”, Santiago de Chile, 17 a 20 de noviembre.

Bournazou, E. (2015). Cambios socioterritoriales e indicios de gentrificación. Un método para su medición. Academia, 6(12), 47-59. Recuperado de http://revistas.unam.mx/index.php/aca/article/view/51982/46330

Carbajal, R. (2003). Transformaciones socioeconómicas y urbanas en Palermo. Revista Argentina de Antropología, 1(1), 94-109. Recuperado de https://www.redalyc.org/pdf/269/26900107.pdf

Carman, M. (2006). Las trampas de la cultura. Los intrusos y los nuevos usos del barrio de Gardel. Buenos Aires, Argentina: Paidós.

Casgrain, A. y Janoschka, M. (2013). Gentrificación y resistencia en las ciudades latinoamericanas. El ejemplo de Santiago de Chile. Andamios. Revista de Investigación Social, 22, 19-44. Recuperado de http://www. scielo.org.mx/pdf/anda/v10n22/v10n22a3.pdf

Clark, E. (2005). The order and simplicity of gentrification. A political challenge. En R. Graham Atkinson y G. Bridge (eds.), Gentrification in a 
global context: The new urban colonialism (pp. 24-30). Oxford, Reino Unido: Routledge.

Comisión Económica para América Latina y el Caribe (CEPAL). (2017). Censos en línea. Recuperado de cepal.org/es/temas/redatam/

Delgadillo, V. (2013). América Latina urbana: la construcción de un pensamiento teórico propio. Entrevista con Emilio Pradilla Cobos. Andamios. Revista de Investigación Social, 10(22), 185-201. Recuperado de https://www.redalyc.org/articulo.oa?id=62828837009

Delgadillo, V., Díaz Parra, I. y Salinas, L. (2015). Perspectivas del estudio de la gentrificación en México y América Latina. Ciudad de México: Instituto de Geografía, Universidad Nacional Autónoma de México.

Díaz, M., Ferme, N. y Raspall, T. (2010). Proyectos de renovación urbana en la zona sur de la Ciudad de Buenos Aires. ¿Hacia una transformación de los usos del suelo urbano? El caso del Distrito Tecnológico de Parque Patricios. Ponencia presentada en las VI Jornadas de Sociología de la UNLP. Universidad Nacional de La Plata, Argentina, 9 y 10 de diciembre.

Díaz Parra, I. (2011). Desplazamiento, acoso inmobiliario y espacio gentrificable en el caso de Sevilla. Encrucijadas. Revista Crítica de Ciencias Sociales, 2, 48-68. Recuperado de http://www.encrucijadas.org/index. php/ojs/article/view/120

Díaz Parra, I. (2016). Política urbana y cambios sociodemográficos en el centro urbano de Ciudad de México, ¿gentrificación o repoblación? Territorios, 35, 127-148. Recuperado de https://revistas.urosario.edu.co/ index.php/territorios/article/view/4136

Galassi, G. y Andrada, M. (2011). Relación entre educación e ingresos en las regiones geográficas de Argentina. Papeles de Población, 17(69), 257-290. Recuperado de http://www.scielo.org.mx/scielo.php?script $=$ sci_arttext\&pid=S1405-74252011000300009

Goicoechea, M. E. (2017). Renovación urbana en el sur porteño y el éxito del Distrito Tecnológico. Algunas claves para comprender el dinamismo inmobiliario. Quid 16. 7, 30-61. Recuperado de https://publicaciones. sociales.uba.ar/index.php/quid16/article/view/2852

Gonzalez, A., Blanco, J., Bosoer, L. y Apaolaza, R. (2015). Movilidades, desplazamientos y territorios: algunos aportes para el debate de la gentrificación (Documento de trabajo 15001, serie III). Leeds, Reino Unido: University of Leeds. Recuperado de http://contested-cities.net/workingpapers/2015/movilidadesdesplazamientos-y-territorios-algunosaportes-para-el-debate-de-la-gentrificacion/ 
Grube-Cavers, A. y Patterson, Z. (2015). Urban rapid rail transit and gentrification in Canadian urban centres: A survival analysis approach. $U r$ ban Studies, 52(1), 178-195. Recuperado de https://journals.sagepub. com/doi/10.1177/0042098014524287

Hammel, D. y Wyly, E. (1996). A model for identifying gentrified areas with census data. Journal Urban Geography, 17(3), 248-268. Recuperado de https://www.tandfonline.com/doi/abs/10.2747/0272-3638.17.3.248

Hamnett, C. (2003). Gentrification and the middle-class remaking of inner London, 1961-2001. Urban Studies, 40(12), 2401-2426. Recuperado de https://journals.sagepub.com/doi/pdf/10.1080/0042098032000136138

Herzer, H. (2008). Con el corazón mirando al sur. Transformaciones en el sur de la Ciudad de Buenos Aires. Buenos Aires, Argentina: Espacio Editorial.

INDEC. (2001). Censo Nacional de Población, Hogares y Vivienda 2001. Buenos Aires, Argentina: Instituto Nacional de Estadística y Censos. Recuperado de http://www.indec.gob.ar/bases-de-datos.asp

INDEC. (2010). Censo Nacional de Población, Hogares y Vivienda 2010. Buenos Aires, Argentina: Instituto Nacional de Estadística y Censos. Recuperado de http://www.indec.gob.ar/bases-de-datos.asp

INE. (2014). Auditoría técnica a la base de datos del levantamiento censal año 2012. Santiago de Chile: Instituto Nacional de Estadísticas. Recuperado de historico.ine.cl/canales/chile_estadistico/censos_poblacion_ vivienda/auditoria-levantamiento-censal.pdf

Janoschka, M. y Sequera, J. (2016). Gentrification in Latin America: Addressing the politics and geographies of displacement. Journal Urban Geography, 37(8), 1175-1194. Recuperado de https://www.tandfonline. com/doi/abs/10.1080/02723638.2015.1103995

Janoschka, M., Sequera, J. y Salinas, L. (2013). Gentrification in Spain and Latin America. A critical dialogue. International Journal of Urban and Regional Research, 38(4), 1234-1265. Recuperado de https://online library.wiley.com/doi/10.1111/1468-2427.12030

Kahn, M. (2007). Gentrification trends in new transit-oriented communities: Evidence from 14 cities that expanded and built rail transit systems. Real Estate Economics, 35(2), 155-182. Recuperado de https:// onlinelibrary.wiley.com/doi/full/10.1111/j.1540-6229.2007.00186.x

Lees, L. (2013). The geography of gentrification: Thinking through comparative urbanism. Progress in Human Geography, 36(2), 155-171. Recuperado de https://journals.sagepub.com/doi/10.1177/0309132511412998

Lees, L., Slater, T. y Wyly, E. (2008). Gentrification. Nueva York, NY: Routledge. 
Lerena, N. (2016). Planificación urbana estratégica, transformaciones territoriales y derecho a la ciudad: el caso del Distrito Tecnológico de Parque Patricios (CABA). Ponencia presentada en las XXX Jornadas de investigación y XII Encuentro Regional SI+FADU, Configuraciones, Acciones y Relatos. Buenos Aires, Argentina, 6 y 7 de octubre.

Levy, D., Comey, J. y Padilla, S. (2006). In the face of gentrification: Case studies of local efforts to mitigate displacement. Washington, DC: The Urban Institute.

Ley, D. (1986). Alternative explanations for inner-city gentrification: A Canadian assessment. Annals of the Association of American Geographers, 76(4), 521-535. Recuperado de https://www.jstor.org/stable/ 2562708? seq=1\#metadata_info_tab_contents

Ley, D. (1988). Social upgrading in six Canadian inner cities. The Canadian Geographer, 32(1), 31-45. Recuperado de https://onlinelibrary.wiley. com/doi/abs/10.1111/j.1541-0064.1988.tb00853.x

Ley, D. (1996). The new middle class and the remaking of the central city. Oxford, Reino Unido: Oxford University Press.

López-Morales, E. (2011). Gentrification by ground rent dispossession: The shadows cast by large-scale urban renewal in Santiago de Chile. International Journal of Urban and Regional Research, 35(2), 330-357. Recuperado de http://repositorio.uchile.cl/handle/2250/145536

López-Morales, E., Bang Shin, H. y Lees, L. (2016). Latin American gentrification. Urban Geography, 37(8), 1091-1108. Recuperado de https:// www.tandfonline.com/doi/abs/10.1080/02723638.2016.1200335

Marcuse, P. (1985). To control gentrification: Anti-displacement zoning and planning for stable residential districts. Review of Law and Social Change, 13(4), 931-952. Recuperado de https://socialchangenyu. $\mathrm{com} /$ review/to-control-gentrification-anti-displacement-zoning-andplanning-for-stable-residential-districts/

Martí, M. y Salazar, M. (2016). Entrevista a David Harvey sobre gentrificación: Habitat III tiene una posición neoliberal. El Canelazo de la Ciudad, 5, 10-15. Recuperado de https://elcanelazodelaciudad.files. wordpress.com/2016/04/canelazo-5.pdf

Pollack, S., Bluestone, B. y Billingham, C. (2010). Maintaining diversity in America's transit-rich neighborhoods: Tools for equitable neighborhoods change. Boston, MA: Dukakis Centre for Urban and Regional Policy.

Ruiz-Tagle, J. (2016a). La persistencia de la segregación y la desigualdad en barrios socialmente diversos: un estudio de caso en La Florida, San- 
tiago. Eure. Revista Latinoamericana de Estudios Urbano Regionales, 42(125), 81-108. Recuperado de https://scielo.conicyt.cl/scielo. php?script=sci_arttext\&pid=S0250-71612016000100004

Ruiz-Tagle, J. (2016b). La segregación y la integración en la sociología urbana: revisión de enfoques y aproximaciones críticas para las políticas públicas. Revista INVI, 31(87), 9-57. Recuperado de http://www.revista invi.uchile.cl/index.php/INVI/article/view/1070

Ruiz-Tagle, J. y López-Morales, E. (2016). El estudio de la segregación residencial en Santiago de Chile: revisión crítica de algunos problemas metodológicos y conceptuales. Eure. Revista Latinoamericana de Estudios Urbanos Regionales, 40(119), 21-48. Recuperado de https://scielo. conicyt.cl/scielo.php?script=sci_arttext\&pid=S0250-71612014000100002

Sabatini, F., Rasse, A., Cáceres, G., Sarella, M. y Trebilcock, M. (2017). Promotores inmobiliarios, gentrificación y segregación residencial en Santiago de Chile. Revista Mexicana de Sociología, 79(2), 229-260. Recuperado de http://www.scielo.org.mx/pdf/rms/v79n2/0188-2503rms-79-02-00229.pdf

Sabatini, F., Robles, M. y Vásquez, H. (2009). Gentrificación sin expulsión, o la ciudad latinoamericana en una encrucijada histórica. Revista 180, 24, 18-25. Recuperado de http://www.revista180.udp.cl/index.php/ revista180/article/view/266/262

Salinas, L. A. (2013). Gentrificación en la ciudad latinoamericana. El caso de Buenos Aires y Ciudad de México. Geographos. Revista Digital para Estudiantes de Geografia y Ciencias Sociales, 4(44), 283307. Recuperado de https://web.ua.es/es/revista-geographos-giecryal/ documentos/luis-salinas.pdf

Sigler, T. y Wachsmuth, D. (2015). Transnational gentrification: Globalisation and neighbourhood change in Panama's Casco Antiguo. Urban Studies, 53(4), 705-722. Recuperado de https://www.researchgate.net/ publication/275653315_Transnational_gentrification_Globalisation_ and_neighbourhood_change_in_Panama's_Casco_Antiguo

Silva, C. (2013). Gentrificación y cambios sociodemográficos en la zona sur de la Ciudad de Buenos Aires, 2003-2010. Ponencia presentada en las X Jornadas de Sociología de la Universidad de Buenos Aires, Argentina, 1 a 6 de julio.

Slater, T. (2009). Missing Marcuse: On gentrification and displacement. City. Analysis of Urban Trends Culture Theory Policy and Action, 13(2), 292-311. Recuperado de https://www.tandfonline.com/doi/ abs/10.1080/13604810902982250 
Smith, N. (1982). Gentrification and uneven development. Journal Economic Geography, 58(2), 139-155. Recuperado de https://www.tandfonline. com/doi/abs/10.2307/143793

Smith, N. (1987). Gentrification and the rent gap. Annals of the Association of American Geographers, 77(3), 462-465. Recuperado de https://lambe threnters.files.wordpress.com/2014/04/smith-n-gentrification-and-therent-gap.pdf

Smith, N. (1996). The new urban frontier: Gentrification and the revanchist city. Londres, Reino Unido: Routledge.

Socoloff, I., Colombo, A., Kitay, I., Maltz, H., Raullansky, I., Seia, G., Stiberman, L. y Urdampilleta, M. (2013). Gobernar Buenos Aires: un estudio sobre las racionalidades políticas en torno al desarrollo local a partir del caso del Distrito Tecnológico de Parque Patricios. Ponencia presentada en las VII Jornadas de Sociología de la Universidad Nacional de La Plata, Argentina, 5 y 7 de diciembre.

Torres, H. (1978). El mapa social de Buenos Aires en 1943,1947 y 1960. Desarrollo Económico 70(18), 163-204. Recuperado de www.rodolfo giunta.com.ar/Historia\%20urbana/Mapa\%20Social\%20en\%20Buenos \%20Aires\%20(Horacio\%20Torres).pdf

Torres, H. (2001). Cambios socioterritoriales en Buenos Aires durante la década de 1990. Eure, 27(80), 33-56. https://scielo.conicyt.cl/scielo. php?script $=$ sci_arttext\&pid $=$ S0250-71612001008000003

Torres, H. (2006). El mapa social de Buenos Aires (1940-1990). Buenos Aires, Argentina: FADU. Recuperado de https://periferiaactiva.files.word press.com/2015/06/torres-el-mapa-social-del-amba.pdf

Wyly, E. y Hammel, D. (1998). Modeling the context and contingency of gentrification. Journal of Urban Affairs, 20(3), 303-326. Recuperado de https://www.tandfonline.com/doi/abs/10.1111/j.1467-9906.1998.tb00 424.x

\section{Acerca de los autores}

Ibán Díaz Parra es licenciado en Geografía por la Universidad de Sevilla y graduado en Antropología Social y Cultural por la Universidad Nacional Española a Distancia. Obtuvo el título de doctor en Geografía en la Universidad de Sevilla y ha realizado dos posdoctorados, el primero en la Universidad Nacional Autónoma de México y el segundo en la Universidad de Buenos Aires. Se ha especializado en el campo de los estudios urbanos, específicamente en procesos de renovación urbana, segregación socioespa- 
cial, gentrificación e impactos del turismo cultural. Actualmente es investigador posdoctoral en la Universidad de Sevilla, secretario de la revista Hábitat y Sociedad y coordinador de la Red Iberoamericana de Investigación sobre Política, Conflictos y Movimientos Urbanos, adscrita a la Asociación Universitaria Iberoamericana de Posgrado. ORCID: https:/orcid. org/0000-0002-4159-3338

Ricardo Apaolaza es licenciado en Geografía y profesor en Educación Superior por la Universidad de Buenos Aires, institución en la que también obtuvo en el título de doctor en Geografía. Ha realizado estudios posdoctorales sobre pasivos del hábitat y movilidad, en el marco del Consejo Nacional de Investigaciones Científicas y Técnicas (Conicet) de Argentina. Es especialista en temas urbano-ambientales y transporte, con énfasis en asentamientos informales y reasentamiento involuntario. Posee amplia experiencia en metodologías de relevamiento socioambiental y manejo de salvaguardas internacionales sociales y ambientales. Es participante de proyectos internacionales de investigación y docente regular o invitado de universidades argentinas, chilenas y paraguayas. ORCID: https://orcid.org/0000-00023684-8623

Recepción: 9 de agosto de 2018. Aceptación: 9 de enero de 2019. 
